\title{
The Impact of Astana Expo2017 on Tourist Destinations
}

\author{
By Alidiya Zamit Seitzhanova*
}

This paper discusses EXPO2017, which was held in the capital city of Kazakhstan Astana. The World Expo is considered to be the third largest global event, after the Olympic Games and the FIFA World Cup, in terms of economic and cultural impacts. In this study, the main question is: "What is the impact of the event on tourist arrivals?" The aim of the paper is to analyze and visualize the dynamics of tourist arrivals not only in Astana, but also in other cities of Kazakhstan to see the regional influence of the event. To achieve the main goals of the study, I used the sign cartographic method, where the main directions of tourist arrivals in Kazakhstan during EXPO2017 are highlighted. In addition, multiple factor analysis is used to simultaneously analyze several tables of variables and obtain results. The study presents an index map that showcases tourist arrivals during the period of EXPO2017. Qualitative and statistical research shows which destinations were popular among EXPO2017 visitors and why those destinations were chosen, as well as which vehicles were used in these destinations. The study uses qualitative analysis, multifactor analysis and map chart programs during data observations. The results of the research yield a list of recommended destinations for further development.

Keywords: sustainable development, tourism, tourism development.

\section{Introduction}

EXPO refers to the World Exhibition, the purpose of which is to demonstrate the latest achievements in the field of industrialization (Walvis 2004). For the countries hosting an iteration of the fair, organizing millions of guests is both a significant honor and a great responsibility (MacKinlay 1997). In 2017, this responsibility was assumed by Kazakhstan (Zamit 2018). Large scale events constitute one of the most exciting and fastest growing impetuses for tourism in many destinations (Yang and Zheng 2012). The World EXPO in general has a major impact on economic drivers and social benefits; specifically, more and more cities are impacted by this and subsequently are hosting different types of large-scale events. These trends clearly influence the development of tourism destinations (Gursoy et al. 2004, Gursoy and Kendall 2006). It is not surprising, then, that tourism is one of the fastest growing sectors of the economy (World Travel \& Tourism Council 2017, Dupeyras and MacCallum 2013, Lankford and Howard 1994, Cornel NJ, Jucan 2013).

The pattern of worldwide exhibitions started in France, where it originated from the tradition of national exhibitions. This tradition culminated with the French Industrial Exposition of 1844, which was held in Paris. This fair was

${ }^{*} \mathrm{PhD}$ Candidate, Szent Istvan University, Hungary. 
followed by other national exhibitions in continental Europe and the United Kingdom. The well-known "First World Expo" was held in The Crystal Palace in London's Hyde Park in 1851, under the title of the "Great Exhibition of the Works of Industry of All Nations" (Findling and Kimberly 2008). The Great Exhibition, as it is often called, was the idea of Prince Albert, Queen Victoria's husband, and is usually considered the first international exhibition of manufactured products. It influenced the development of several aspects of society, including art and design education, international trade and relations, and tourism. This Great Exhibition was the most obvious precedent for the many international exhibitions to come; these have later been called world's fairs and they continue to this day. However, since their inception in 1851, the character of these World Expos has evolved. Three eras can be generally distinguished: the era of industrialization, the era of cultural exchange, and the era of nation branding (World Expos 2015).

One of the main aim of the study is to analyze the impact of the EXPO. Many other worldwide events proven their non-reason west or significance (Kim et al. 2006, Kim et al. 2002). In 2017, the World Expo was hosted by Kazakhstan. Held in the capital of the country, the Astana EXPO 2017 created many opportunities for Kazakhstan, from modernization of the energy sector and optimization of transport infrastructure to a breakthrough in tourism and strengthened international cooperation. The most important achievement of the event was undoubtedly the integration achieved between countries. Shaping an integral and attractive image of the country in the international perspective is often perceived as a secondary effect, the benefit of which does not always seem immediately obvious. However, in a world where the quality and nature of goods and services are increasingly less connected with their place of origin, it is not so much the competition of products that comes to the fore. Instead, this competition between reputations is achieving heightened focus. The national and international media coverages of a certain event (for example British Open, Sydney 2000 Olympics) make considerable references to the town, the local scenery, nearby venues, the standard of accommodation, local people, and transport networks (Gelan 2003, Hall 1996). Such experience in Europe made a challenge to Astana to get the similar results in Central Asia.

To showcase these developments, this study gives an overview of the qualitative analysis of 81 interviews conducted with participants of EXPO2017 (Baker 2012). The respondents came from 45 countries to the capital of the Republic of Kazakhstan - Astana. This overall report is based on qualitative reports analyzed as part of the authors' docroral research. The aim of this research is to determine if the visitors to EXPO2017 were willing to visit other destinations apart from Astana. The research complements these questions quantitatively by regarding relationships to various individual dimensions (i.e. change of attitudes, self-concept, mentality, behavior) and social dimensions (i.e. status, family life, social networks). The following objectives were maintained throughout survey distribution and analysis: 
- determine the main groups among EXPO visitors;

- determine their past experiences, if any, in Central Asia;

- measure their willingness to visit other destinations while attending EXPO;

- measure their awareness about available transportation options in Central Asia;

- discover the main destinations visited during the Astana EXPO2017.

To answer these questions, all respondents' feedback about their participation in EXPO 2017, their experiences, and their perceived impacts of the event were analyzed. One of the main goals of the research was to fulfill the authors' curiosity regarding whether Shymkent or neighboring countries like Uzbekistan and Kyrgyzstan also gained visitors from the large-scale event. By recording these visitation patterns, as well as people's attitudes towards the region, we hoped to discover the factors that are critical determinants for tourism flows, levels, and experiences.

Regarding such topics under study, our hypotheses were the following:

- H1: The agreement between Kazakhstan's government and WizzAir will attract many visitors not only to Kazakhstan, but also to neighboring countries, such as Kyrgyzstan and Uzbekistan.

- H2: Time limitations and long distances are obstacles to traveling in the southern regions of the country.

- H3: After their experiences at EXPO, travelers will be willing to visit the region again.

Additionally, the paper briefly addresses some specific aspects that appear to have an impact on potential improvements in the country and region regarding tourism development. Although these certain aspects of national identity are among the research questions formulated in the course of the research, these are not at the core of the work since the comparison of interests from different nationalities is not within the scope of this paper. These therefore form the basis of our recommendations for further research. However, basic awareness of these national characteristics is needed to assure an adequate interpretation of the results where appropriate.

\section{Methodology}

\section{Data Collection and Research Design}

A qualitative survey was distributed in ten different locations in order to gather data for this research. This aimed to be a large-scale survey with individuals who had come from 115 different countries to attend EXPO2017. The survey provided information about general levels of interest in the city and the scale of its recognisability. The surveys contained 21 questions, including preliminary inquiries about demographic information and open-ended questions 
about the respondents' perceptions of the attractiveness of tourism opportunities in the region. Many previous interviews with scientific purposes were considered in this study in order to avoid the mistakes (Jeong 1998, Kang Long et al. 1996, Kim and Petrick 2005). The first part of the survey was easily analyzed using $\mathrm{R}$-commander program for sorting, while the second part required a long and careful decoding.

Certain respondents to the survey were selected for further analysis. All interviews followed the rules about conversation ethics and interview rules (Atkinson and Heritage 1984, Heritage 1988) subsequently, 81 qualitative interviews were conducted. The rationale behind this was to provide more indepth and contextualized insights into how people perceive a general image of the hosting city - Astana - as well as other large cities in the region. All interviews were carried out and fully transcribed. The resulting data body comprises approximately 900 pages of interview transcripts with between 10 and 20 pages per interview. The first part of the interview gathered general demographic and social information. The second part of the interview asked ten open-ended questions, which were classified by the most commonly mentioned criteria, factors and data. These answers were tabulated to make graphs for the visual perception of the results.

These qualitative interviews provide more "rich" information about what makes the city attractive and what things have to be taken into consideration to improve the attractiveness. Respondents also had opportunity to indicate precise reasons that led them to visit or not visit the city. Such results aimed at complementing the survey data by providing rich and unstandardized data, thereby obtaining an overall more accurate picture of the participants. Incidentally, the interviews also allowed us to grasp the culturally different perceptions of tourist attractiveness. This is particularly useful in the context of a comparative study (Berg 2001).

\section{Qualitative Analysis}

This report presents the findings of a series of interviews with women and men of various age groups and educational levels who were in Astana in the summer and autumn of 2017. Only foreign people were interviewed in order to avoid certain local attitudes considering that there is competition between the capital and the other large cities in the country. Respondents were asked about the attractiveness of the region from a tourist point of view, as well as about the difficulties they met when they wanted to visit a city. People were interviewed not only within the EXPO area, but also in various city locales, such as malls, coffee shops, restaurants, hotels, the airport and train station. It was our hope that this qualitative research would provide details about relevant human behaviors, emotions, and personality characteristics, which quantitative studies cannot match. Qualitative data also includes information about user behaviors, needs, desires, routines, use cases, and a variety of other information that is essential in designing a desirable and functional product (Day 2005, Sgier 2014, Zhang and Wildemuth 2005, Flick 2013). 


\section{Map Chart Program}

Map Charts is a GIS program that allows us to position any data in a context, often geographical, using different layers. The layers can be either data layers, such as marker layers or feature layers, or reference layers, such as map layers. A map chart allows us to visualize spatial relationships in the data by indicating data on a geographical map. Explore Analytics provides two main types of map charts: geographical points and geographical areas. Geographical Points show data points on a map by indicating markers at geographical coordinates. This method is similar to the way that an XY chart places points at coordinates along axes. The marker can vary in its shape, color and size. The marker itself can even be a pie chart, as we will see later. This type of map chart is known as a bubble chart. On the other hand, Geographical Areas show color areas on a map to indicate a value or a category of data for an entire area. For example, areas could be states of the United States, and their color could indicate a numerical value for each state. This type of a map chart is known as a choropleth.

Multiple Factor Analysis

Another method for data analysis and result visualization utilizes multiple graphs in a process known as Multiple Factor Analysis (MFA). MFA is used to simultaneously analyze several tables of variables and to obtain results, particularly through charts, that allow us to study the relationship between observations, variables and tables (Novak 1990).

\section{Ethics}

All interviewees gave their explicit consent to being interviewed and audiorecorded. They were informed of the context of the study and the use of their data. The interview data were anonymized. The interview transcripts contain no information allowing us to link the interview data to the survey responses of the interviewee. To further preserve the anonymity of the interviewees, the list with the full demographic characteristics of our interviewees (such as place of residence, name of course providers, employment status, etc.) is not integrated in the present report.

\section{Results}

There were over one hundred countries that took part in EXPO 2017, though fewer were represented by the survey. Overall, people from 45 countries were interviewed. Respondents were mainly from countries in America, Eurasia and Africa. Regarding the age of the respondents, they were divided into four groups: A (younger than 24), B (25-29), C (40-55), and D (older than 55). The numbers of male and female respondents were almost equal. These results are shown in Figure 1. 
Figure 1. Respondents' Age and Origin

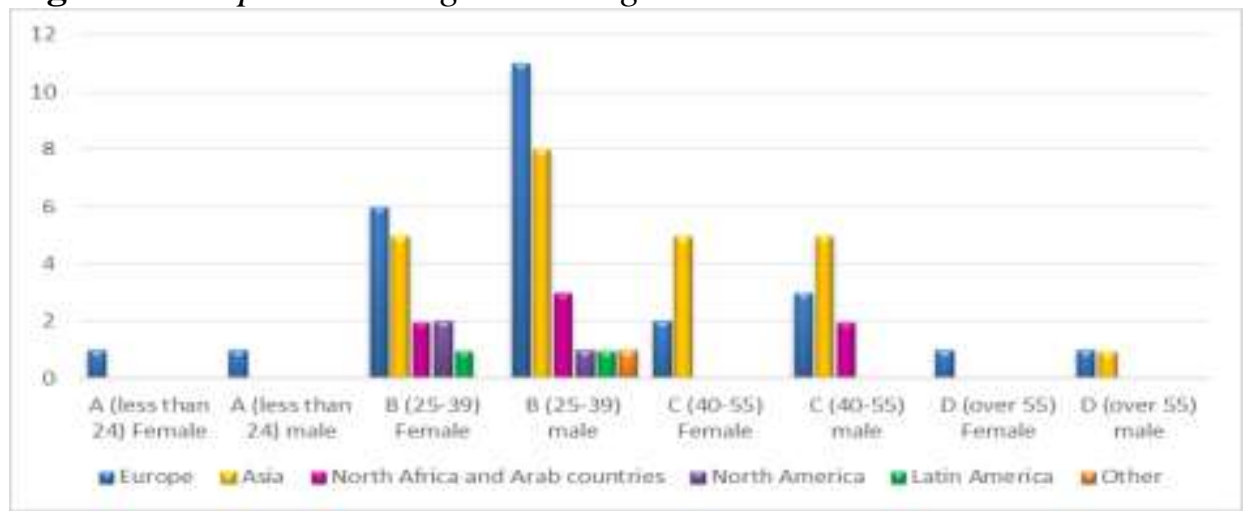

Source: own compilation based on survey result, 2018

As can be seen from the Figure 1, the majority of respondents belonged to the $\mathrm{B}$ and $\mathrm{C}$ groups, in other words between 25 and 55 years of age. Moreover, most of them were from European and Asian countries. For further detail, it is important to mention that most Europeans came from Eastern and Central European countries and respondents from Asia mainly came from South Korea and China.

The breakdown of ages of participants can be partially explained by their occupations. As addressed by the fifth question of the survey, a majority of respondents interviewed were "travel-oriented" employees. A vast majority came for business purposes or other job related issues. Mainly, respondents were businessmen and travelers, who visit different countries for a long period, as well as travel bloggers and digital nomads. All people who described themselves as travelers, travel-bloggers or photo-bloggers were grouped together in an "other" category. These results are shown in Figure 2.

Figure 2. Occupancy

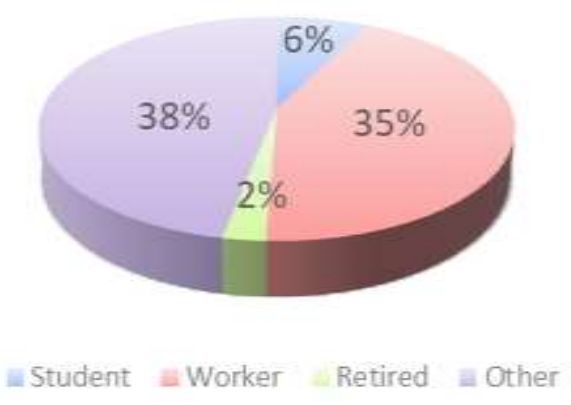

Source: own compilation based on survey result, 2018

Seventy-five respondents out of the 81 interviewed were visitors to Kazakhstan for the reasons listed above; however, three of them were expats working in the country. This may inspire certain conclusions about the expat community, such as that there are few expats in the country, they were not likely to visit the EXPO, or they were too busy to allow themselves to be interviewed. As the official statistics of the Agency of Republic of Kazakhstan 
show the number of recorded expats living in the country, the second or third suggestions listed are more likely. However, speculations of this kind are not the purpose of this research.

Other questions addressed the study's primary topics of interest, namely which countries and cities attracted EXPO2017 visitors. All respondents were willing to visit more places, especially when able to take advantage of direct flight opportunities. Popular destinations during the Astana EXPO2017 are shown in Figure 3.

Figure 3. Popular Destinations in Central Asia during Astana EXPO2017

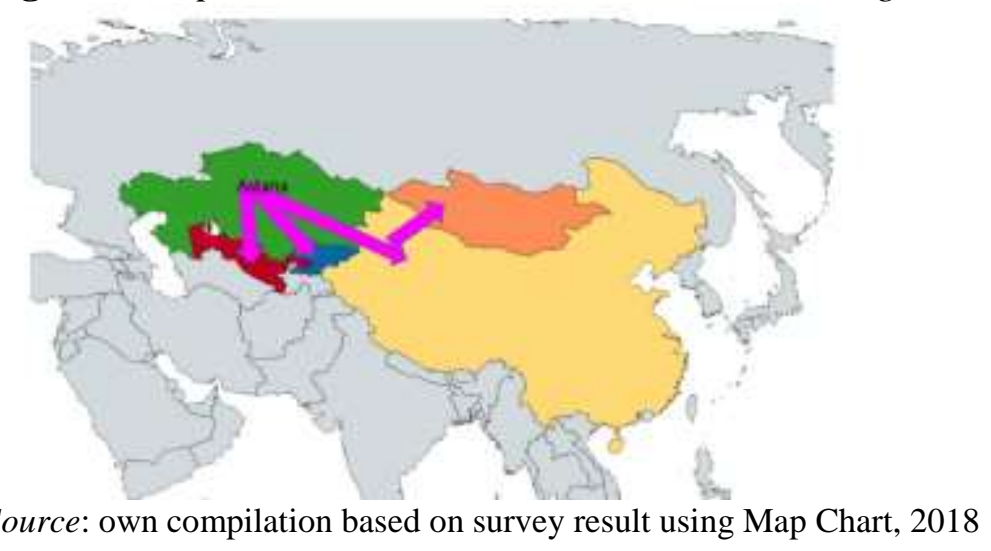

The main goal of the interviews was originally to determine which destinations visitors would most like to visit in Central Asia. This is clear in the above depiction. Surprisingly, during this inquiry all of the interviewed respondents replied that they would like to visit Almaty. During this discussion process, it was discovered that people who came for the EXPO actually had done some research about Kazakhstan and realized that this city is more attractive than the capital. After this surprisingly unanimous response, the goal of the research naturally shifted to a determination of why visitors had particular interests and how their experiences turned out if they were able to visit different destinations in Central Asia (Dellios 2017).

Astana EXPO2017 had an impact on tourist destination development not only in Central Asia, but also in Europe. Many tourists traveling to Central Asia used WizzAir's direct line between Budapest and Astana. Over 50\% of respondents mentioned that they had stopped in Budapest or other European cities for a few days to enjoy the city on the way to Astana or that they were planning to do so on their way back. This new line created opportunities for the whole Central Asian region. Mountain lovers, hikers and alpinists chose Kyrgyzstan for its high mountains. History lovers went to Uzbekistan to see the cities with UNESCO heritage sites from the middle Ages, such as Samarqand and Bukhara. For travelers who dreamed of visiting Mongolia, it seemed a great opportunity to go there via a bordering country. Because there are no direct lines between Mongolia and Kazakhstan, tourists discovered that China was the only transit option. Thus the impacts of the EXPO extended to yet another destination. 
As a region home to outstanding natural landscapes and cultural heritage sites that transcend individual countries, sustainability is a vital issue for the Silk Road. By agreeing upon a common approach, Silk Road countries agreed to advance the 2030 Sustainable Development agenda ( $7^{\text {th }}$ UNWTO Silk Road Ministers' Meeting 2017). One of the main steps in this regards is simplifying visa issues in Central Asia. Thus, Kazakhstan is open for more than 60 countries, Uzbekistan change to online visa procedure in 2017. Visa facilitation is central to stimulating growth and job creation through tourism. In spite of the great strides made in recent decades to facilitate tourist travel, there are still important areas of opportunities to improve visa procedures (ITB Berlin 2014).

Taking these results into account, we see that the hypotheses formulated at the beginning of the research were sound. Three hypotheses were given, and all of them were not rejected. The first hypothesis argued that the agreement between Kazakhstan's government and WizzAir will attract many visitors not only to Kazakhstan, but also to neighboring countries, such as Kyrgyzstan and Uzbekistan. As was reported, all interviewed people were interested in visiting a few Central Asian countries. The second hypothesis predicted that despite this interest, people would be limited by time and distance. Accordingly, 45\% of the respondents reported that they were not able to visit different cities or countries due to having only a short period of free time. Such obstacles led logically to the third hypothesis. We assumed that after their experiences at EXPO, travelers would be willing to visit the region again. And indeed, at the time of the interviews, 55\% of the respondents had visited or were planning to visit the region again. Finally, we discovered an outcome that we had not predicted in our hypotheses: the impact of Astana EXPO2017 on the tourism development of other cities, especially Budapest.

Taking these confirmations into account, the following recommendations can be made in the case of a larger study. Return or repeat tourism is one of the best indicators of the tourism industry overall, and it is actually the thing that destinations, particularly cities, are trying to achieve. Once there is a positive trend for this indicator, the city can be considered a successful and attractive destination for tourists. There are two main takeaways from this research and its corresponding recommendations. First, Kazakhstan made an effort to involve WizzAir in the country for minimum costs at the Astana International Airport in order to attract visitors to the country. Second, it cannot yet be determined which party benefitted most from such an arrangement. It was obviously a historical and satisfactory agreement for all sides.

\section{Conclusion}

This paper aimed to discover the impacts of the Astana EXPO 2017 on tourism activities during the event. We hoped to shed light on which destinations were popular during the EXPO 2017, as well as the reasons and indicators for such popularity. EXPO respondents were interviewed with open-ended questions. 
Each question was examined, sorted and analyzed. The main findings of this analysis are outlined below.

The primary visitors to the EXPO 2017 were travelers or business workers who were curious about Central Asian countries. Their interest in Central Asian countries was bolstered by the ease of obtaining a direct flight from Budapest to Astana. In making preparations for their trips, most researched the area and were drawn to particular sites. Popular cities in Kazakhstan were Astana, Almaty and Shymkent. Popular cities in the nearby country of Uzbekistan were Tashkent, Samarqand and Bukhara. Kyrgyzstan was attractive for its natural sites, including Issykkul Lake and the Kungei Mountains. Various destinations in China and Mongolia also piqued people's interest. Despite declared interests, not all of these sites were visited. The vast majority of these visitors were not able to visit other places due to limited time. Instead, more visitors were able to make trips to other European destinations through the Budapest connection.

Regardless of this limited time, the Astana EXPO2017 had an impact on the tourism development in other places. Some visitors were able to travel, while others made future plans to do so. This is representative of the obvious positive influence of large-scale events. Astana EXPO2017 had an impact not only within the country, but also in Central Asia as a region. Moreover, tourism development occurred in Hungary. Thus, it was clearly a geographically expanded event. This created many opportunities for all involved parties.

As such, the impacts of the event on the development of tourist destinations is clear. However, it is important to mention that these occurrences are more related to the scale of the event, rather purpose. Therefore, it is a good idea for states to organize such events, with a focus those that are cheaper to implement, promote cooperation, involved many actors, and keep people within a country for a longer period of time. This could be, for example, a grant program for researchers in Kazakhstan. Overall, the impact of EXPO2017 on many destinations was huge, and the government and cities should learn from this experience and make efforts develop proactive initiative and cut out potential setbacks.

\section{References}

Atkinson JM, Heritage J (1984) Transcript notation. In J. M. Atkinson \& J. Heritage (Eds). Structures of social action: Studies in conversation analysis, 9-16. Cambridge: Cambridge University Press.

Zamit A (2018) Qualitative analysis of Almaty tourist attractiveness by Astana EXPO2017 visitors' view. "The Silk Road and the Tourism and Hospitality Industries". Proceedings of the $15^{\text {th }}$ KIMEP Joint International Research Conference. Kazakhstan: Bang College of Business.

Berg BL (2001) Qualitative Research Methods for the Social Sciences. Boston: Allyn and Bacon. Chichester: John Wiley and Sons.

Cornel NJ, Jucan (2013) MS.Travel and Tourism as a Driver of Economic Recovery. Journal Procedia Economics and Finance 6. 
Dupeyras A, MacCallum N (2013) Indicators for Measuring Competitiveness in Tourism: A Guidance Document. OECD Tourism Papers, OECD Publishing.

Gelan A (2003) Local economic impacts the British Open. Annals of Tourism Research 30(2): 406-425.

Gursoy D, Kendall KW (2006) Hosting mega-events: modelling locals' support. Annals of Tourism Research 33(3): 603-623.

Gursoy D, Kim K, Uysal M (2004) Perceived impacts of festivals and special events by organizers: an extension and validation. Tourism Management 25: 171-181.

Hall CM (1996) Hallmark events and urban re-imaging strategies: coercion, community, and the Sydney 2000 Olympics. In L. C. Harrison \& W. Husbands (eds). Practising Responsible Tourism: International Case Studies in Tourism Planning, Policy and Development, 366-379.

Heritage J (1988) Current developments in conversation analysis. In D. Roger \& P. Bull (Eds). Conversation: An interdisciplinary approach, 21-47. England: Multilingual Matters.

Day I (2005) Qualitative data analysis. A user-friendly guideline for social scientists. London and New York: Routledge Tailor\&Francis Group.

Sgier I (2014) Qualitative Data Analysis Report Analysis of the BeLL interviews in 10 countries: overall report. Swiss Federation for Adult Learning SVEB.

Jeong GH (1998) Residents' perceptions toward the tourism impacts of the '93 EXPO development on the city of Taejon. Journal of Tourism Studies 18(1): 153-173.

Findling JE, Kimberly DP (2008) Encyclopedia of World's Fairs and Expositions, 13-14.

Kang YS, Long PT, Perdue RR (1996) Resident attitudes toward legal gambling. Annals of Tourism Research 23(1): 71-85.

Kim HJ, Gursoy D, Lee SB (2006) The impact of the 2002 World Cup on South Korea: Comparisons of pre- and post-games. Tourism Management 27(1): 86-96.

Kim SS, Prideaux B, Kim S (2002) Across-cultural study on casino guests as perceived by casino employees. Tourism Management 23(5): 511-520.

Lankford SL, Howard DR (1994) Developing a tourism impact attitude scale. Annals of Tourism Research 21(1): 121-139.

Yang LT, Zheng G (2012) Capacity optimization analysis for the MICE industry in Las Vegas. International Journal of Contemporary Hospitality Management 24(2): 335 349.

MacKinlay AC (1997) Event Studies in Economics and Finance. Journal of Economic Literature 35(1): 13-39.

Novak JD (1990) Concept maps and Vee diagrams: Two metacognitive tools for science and mathematics education. Instructional Science 19: 29-52.

EXPO (2017) Retrieved from https://bit.ly/2KUIRIe.

Kim SS, Petrick JF (2005) Perceptions of the Impact of 2010 EXPO 175 Residents perceptions on impacts of the FIFA2002 World Cup: The case of Seoul as a host city. Tourism Management 26(5): 25-38.

Zhang Y, Wildemuth BM (2005) Qualitative Analysis of Content. School of Information. The University of Texas at Austin.

Dellios R (2017) Silk Roads of the Twenty-first Century: The Cultural Dimension. Asia \& Pacific Policy studies 4.

Baker SE (2012) How many qualitative interviews is enough? Expert voices and early career reflections on sampling and cases in qualitative research. National Centre for Research Methods Review Paper. Middlesex University Rosalind Edwards, NCRM, University of Southampton, 10.

$7^{\text {th }}$ UNWTO Silk Road Ministers' Meeting 2017 Sustainable Tourism and Local Silk Road Communities. 
Flick U (2013) The SAGE Handbook of Qualitative Data Analysis.

ITB Berlin (2014) Tourism visa Openness report for the Silk Road countries.

World Travel \& Tourism Council (2017) Travel \& Tourism Global Economic Impact $\&$ Issues report.

Walvis T (2004) Three eras of World Expositions: 1851-present. Cosmopolite: Stardust World Expo \& National Branding Newsletter. Amsterdam: Stardust New Ventures. 
